\title{
A Trackable Augmented Learning Media System for a Higher Education Level
}

\author{
https://doi.org/10.3991/ijet.v14i13.10177 \\ Supadaech Chanjaradwichai, Jaitip Na-Songkhla $\left({ }^{\bowtie}\right)$, Thanyaporn Chiasiriphan \\ Chulalongkorn University, Bangkok, Thailand \\ jaitip.nechula.ac.th
}

\begin{abstract}
Learning material is one factor that affects the performance of teaching and learning with a learning management system (LMS), so this research presents a trackable augmented learning media system that contains a trackable learning material and a cloud-based LMS. The trackable learning material consists of a printed book and a mobile application. The application augments a virtual reality to a printed book, keeps a student learning log and sends it to the LMS. The proposed LMS contains only the required functions to work with the trackable learning material, which are the teacher registration, classroom management and report generating functions. Teachers need to operate the LMS manually. The collected students' learning log automatically generates reports in the LMS that show the performance and behavior of the students, information that the teachers can then use to adjust the pedagogy to be consistent with their students.
\end{abstract}

Keywords-Learning Management System, Augmented Reality, Learning Log, Trackable Learning Material

\section{$1 \quad$ Introduction}

Learning management system (LMS) is an information management system that consists of several tools focused on the improvement of class management efficiency. Classroom management efficiency can be classified into the two perspectives of classroom management and the experience of the learner (hereafter student), and they result in both the instructor (hereafter teacher) and student gaining more advantages from the LMS [1-3]. The LMS has been developed with a specialized tool to improve the student's experience, i.e., using a group video conference tool to promote interaction among students in the class [4].

For the implementation of LMS in Higher Education classrooms, Holt and Challis [5] showed that applying LMS did not result in better experiences for both the students and teachers, while Romi [6] presented that the teacher, information communication technology (ICT) and the assigned task affected the performance of the student. The four critical factors that affect the LMS outcome are discussed as follows.

(i) Learning the employment of the LMS system [7]: The LMS system requires both the students and teachers to understand the employment of the system. The most 
common problem is the application of the LMS system without training or the user manual for students and teachers to acknowledge or understand, which will result in the users having difficulty to locate the instructions or methods to complete the tasks. Applying an LMS with many extra useful tools above those essential for its purpose without an inactive function would result in many options in the system being seldomly used and those options would potentially increase the time and difficulty for the user to find the desired function.

(ii) The LMS system does not provide the ability to easily complete some tasks [8]: For example, in the case of giving feedback on homework back to the students, when it is the original paperwork, the teacher can simply note down the feedback directly on the paper, but when submitting the homework as electronic files, such as image files, the teacher needs to note down only comments in the text box provided, as it is not allowed to draw any lines or symbols. Electronic files would hence make the teacher feel cumbersome and unfamiliar with its use.

(iii) Learning material and pedagogy are not suitable with LMS $[9,10]$ : As the teaching materials and worksheets used in Higher Education are in the form of a hard copy, such as textbooks, the students need to work in the worksheet and send it as a hard copy, which is not suitable for engaging in the LMS system.

(iv) Lack of IT support for problems solving [10, 11]: Since there are many functions that the teachers are not allowed to perform on their own, they have to expect the Administrator to create the new course or even amend data, such as the username and password when the password is forgotten. However, if the IT support cannot resolve the issue quickly, it will result in the users (teachers and students) feeling discontent and difficulty in the use of the system as they cannot perform their work continuously.

However, a cloud-based LMS [12] is proposed to solve this problem, where the LMS is installed on a single server and provided to many institutes in a software as a service (SaaS) model. This can reduce the installation and maintenance cost, especially since the IT staff are employed by a single party to support a whole institute making it more cost effective and with a higher performance than when letting institutes manage it by their own team.

Investigation of the available data science research revealed that numerous types of information were recorded in a LMS, and these data can be employed to analyze the behavior of the students [13].

The problems mentioned above are a factor related to the learning material and pedagogy as textbooks and worksheets are not designed for application with LMS from the beginning, causing the teachers to potentially experience that they have inadequate access to valuable information from their original operations. Compared to a non-LMS, the teacher still collect scores from the student's worksheet, which can result in the teacher considering that using the LMS does not provide them with more benefits but rather wastes their time on learning how to use the LMS. In addition, the teacher may perceive that the system gives them a higher workload and so they do not wish or need to use the LMS [8].

Therefore, in this research, the learning material and LMS were simultaneously designed in a system called the trackable augmented learning media system. This supports the teachers in outlining a more effective teaching system using the new pedagogy and 
allows the student to learn from the augmented reality (AR) technology, both in class and individual perspectives. Each student's learning activities are collected and sent to the system. The teacher can then utilize that information in this system and analyze the behavior of each student.

\section{Research Methodology}

This research was based upon developing the LMS and learning materials together as both of them must be applied in parallel. For the proposed LMS, it can be employed with other learning materials designed to send a learning log back to the LMS. A data flow diagram of the proposed system is shown in Figure 1. The data that is taken into the system are collected from the three origins of the

- Information from teachers via registering and creating a new classroom function of the LMS system

- Information retrieved from students via the registration function of a learning material application

- Learning log data collected while students use the learning material application.

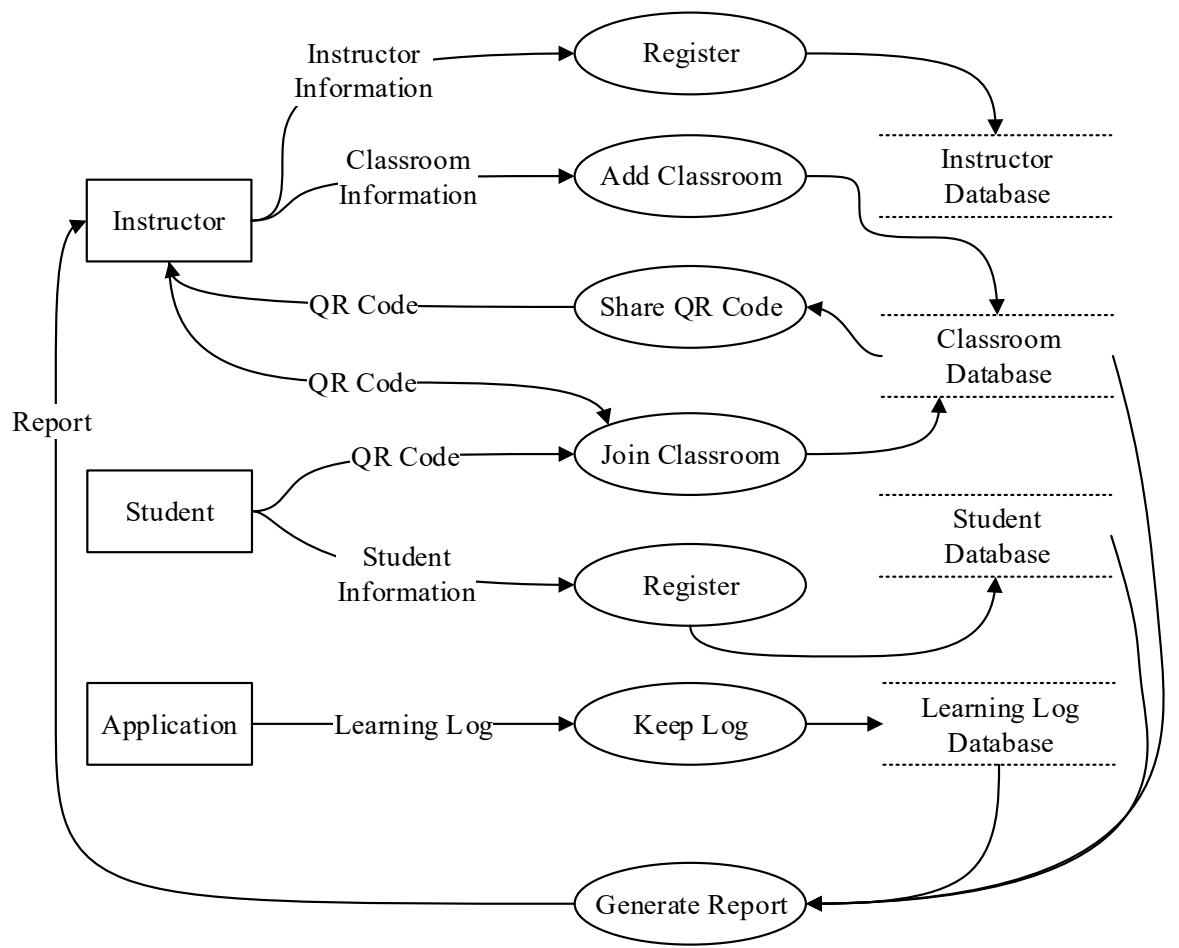

Fig. 1. Data flow diagram of the proposed system

The details of each component in the data flow diagram are explained as follows. 


\subsection{Learning material}

The learning material introduced in this research is digital media to apply to the information system to collect information obtained during the course, along with the addition of the AR technology to allow students to be more interested in this learning material [14]. The device for showing the augmented information is a mobile device with an Android or iOS operating system, and in this manuscript the learning material is named hereafter as the AR Book.

The AR Book is presented in the manner of comic printed books giving the knowledge in electrical circuits and equipped with the specific mobile application for augmenting more content and sending the learning log to the LMS system. The AR Book is comprised of two parts as follows.

Content: The content of the teaching will be in the copy of a book, in which some pages come with additional results with AR technology, similar to those previously presented $[15,16]$. When students point a mobile device to an image marked with the virtual reality icon, the application will display augmented information. The application automatically records the time the student used to study the content and stores it in the LMS system.

Examination: The examination is designed in a similar format to multiple choice questions but augmented with AR technology to provide more realistic questions. During the examination, the student can check their answer instantly, and when it is incorrect, the application will display a hint message depending on student's response and allows them to choose a new answer option until the question is answered correctly. The examination is completed when the student has answered all the questions correctly.

Examinations printed in the AR Book appear in a questioning frame, as shown in Figure 2, called an examination page. The examination page is divided into the two parts of the top section, which shows the sub-questions selector, and the bottom section, which shows the simulated situation. As an example, in an electrical circuit lesson, in the bottom section of Figure 2, displays a circuit with two empty answer slots.

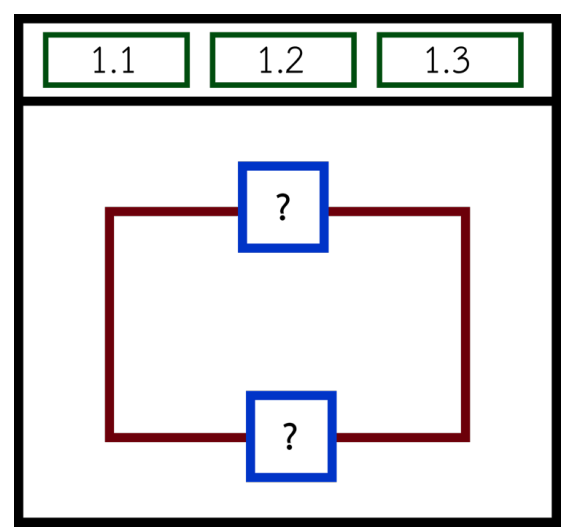

Fig. 2. The examination frame printed in the AR book. 
After launching the AR book application and scanning the image of the area where the examination situation is located, the learning lesson will appear in a mobile device as shown in Figure 3A. At the top of the application, there is a command for the user to perform the next task. On the right side of the application, there is a selection of electrical devices that can be selected (displayed when the student taps at the sub-question). If a student enters this practice for the first time, the application instructs the student to select the desired sub-question. They must tap on the sub-question (with numbers 1.1, 1.2 and 1.3) on the top of the application for the first step.

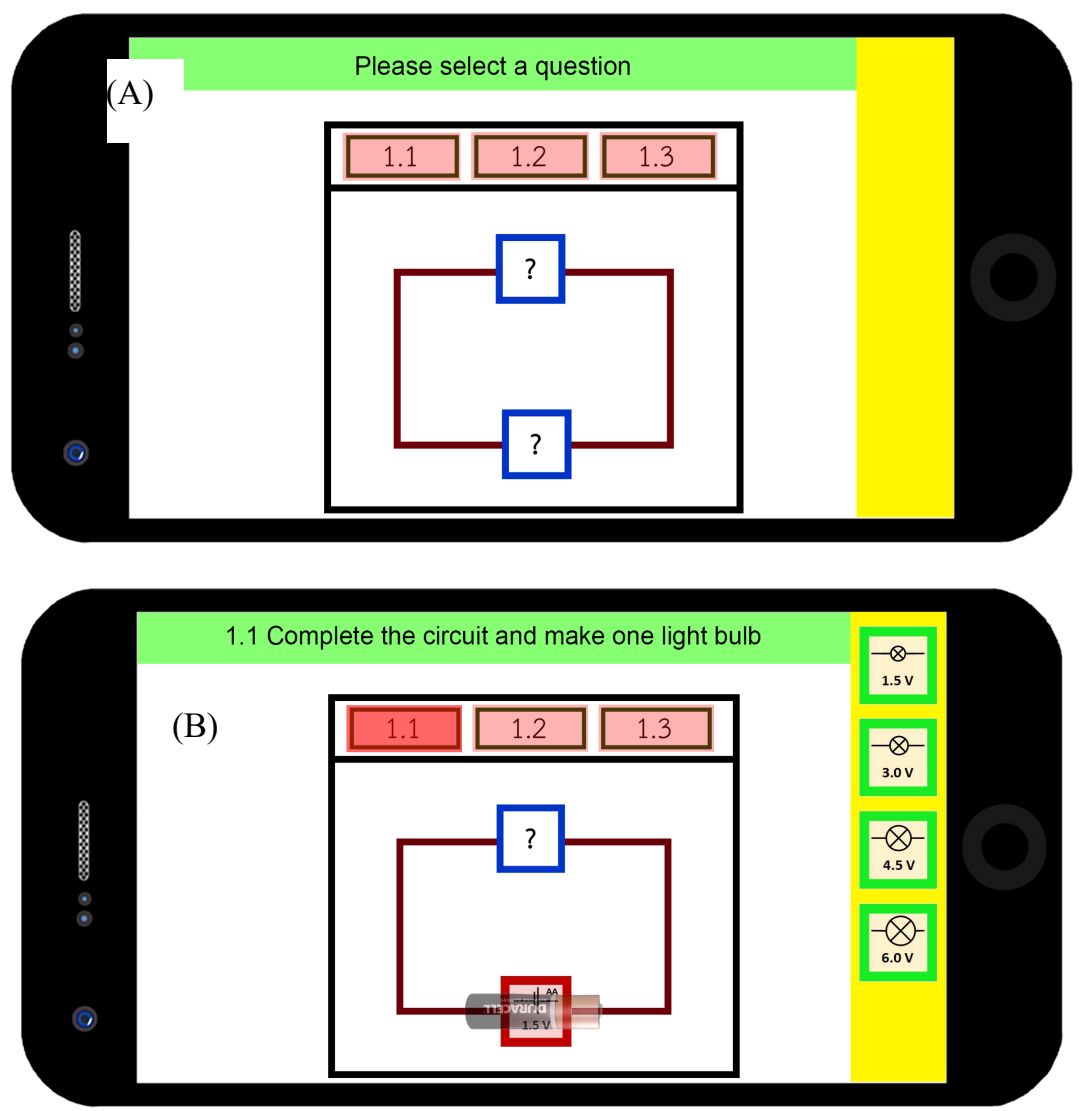

Fig. 3. Example of an application screen (A) with the examination and (B) when selecting the question

As the student choses a sub-question, the application will show more information in the bottom part and ask the student to choose electrical components to complete the circuit, as shown in Figure 3B. The student can choose any electrical component in the right side as an answer to the examination, as shown in Figure 3B. Sub-questions and options that the student choose to answer are different according to the difficulty of the contents. 
When the student has finished choosing an answer to a circuit, they click on the "Submit Answer" button. The system will check the answer and promptly return the results to the student. When the student answers incorrectly, the application will show a hint and let them try again until the student answers the question correctly.

An examination that is designed in this manner focuses on the student's learning from practice and provides an opportunity to connect the circuit in a simulation environment. It does not cause any harm and has more participation than measuring results, and so gives a better outcome than taking a test and submitting it to their teacher because the latter creates a higher workload and amount of time for the teacher to grade the student's assignments before returning them to the student [17].

The information obtained from this practice section consists of

- The length of time that the student used to practice, separated into each examination and sub-question

- All answers that the student chose for each sub-question, including whether the answer was correct or not.

Student registration: When the student launches the application for the first time to complete an assignment that the teacher assigned, the student is first required to register. The registration isn't linked to other applications or social media accounts, such as Facebook or Gmail. The student information used in the registration process contains the following information.

- A photo is taken from the application (required)

- First name and last name (required)

- Education college (optional)

- Student's e-mail (optional)

The application registers the student information with the unique mobile device hardware number. Therefore, a student does not require to enter their username and password to access the system. However, authentication using a mobile device hardware number has the disadvantage of when a student changes their registered mobile device it is necessary to register as a new user. The system then considers the user as a newly registered user and does not relate this to the user registered with the previous mobile device. Therefore, the data must be linked to let the LMS system know which accounts represent the same student by the teacher. This is detailed more in Section 2.2.

\section{2 $\quad$ Proposed LMS}

The proposed LMS is developed as a web application, and the teacher can access the website via the specified URL. It is recommended to use the Google Chrome web browser on a smartphone or computer to display the website. Also, the LMS system architecture is designed to be compatible with many institutions, so there is no need to separate the installation according to the various institutions.

The proposed LMS is hereafter referred to as WeLearn LMS. 
Functionality: The WeLearn LMS design principle is focused only on the components that are related to the AR Book, and so the features that WeLearn LMS contains are as follows.

- Registration for the teacher

- Create a course or classroom

- Generate QR code for students or co-teacher(s) to access the class.

- Manage students in the classroom and as co-teacher(s)

- Display a summary report of students from the information received from the AR Book application (sections 2.1.1 and 2.1.2)

It was found that only five features correlated with activities in the study. Most of the critical LMS features, such as the discussion board, announcement board, course material and assignment, are not included in the proposed We Learn LMS for two main reasons:

(i) User-friendly: Due to the requirement for teachers to experience a user-friendly application, the We Learn LMS is designed to have only the essential features. This results in the user interface of the system having only a few buttons and takes less time to study how to use it. Teachers can perceive a better experience with the We Learn LMS compared to a fully functional LMS.

(ii) Replacement of other options: Because of the social conditions in Thailand, where there is a high usage of social media, most higher education students have their own social media accounts and so the teacher often uses social media as the discussion board, announcement board and course material feature, instead of using the LMS. Also, research has shown that using social media instead of a LMS can improve the educational achievement of the students [18].

An example of another option LMS is Kahoot [19], a specific purpose LMS designed as an in-class and real-time quiz generator. Bicen [20] studied the student's perception of the Kahoot application and reported a good level of student satisfaction with it.

Initialize the process: WeLearn LMS encourages the teachers to manage their classrooms by adding classrooms and managing student lists. For this feature, the teachers need to learn more to get familiar with the system, which may initially give the teacher some difficulty. However, they can control the class settings on their own and do not need to wait for the administrator to handle the problems in this section. The detail of each step in the initial process is described as follows.

(i) Register: This step is the process of registering teachers to access WeLearn LMS. The information required for registration is the teacher's name, school or college, telephone number, e-mail and social account. WeLearn LMS provides authentication with a social media account, such as Gmail or Facebook. Therefore, once registered teachers do not have to remember their username and password.

(ii) Add classroom: This step identifies the process for adding a classroom to WeLearn LMS, so that teachers can easily manage and classify students. The required information for adding classrooms are the subject of the AR Book used in the classroom, classroom name and an icon of the classroom. One classroom can apply multiple AR books (applications), but it is required to address the contents in the first 
AR book to prevent students from accessing other contents to study in the wrong class or lesson.

(iii) Share QR code: After creating a classroom, WeLearn LMS generates a QR code of the classroom. This $\mathrm{QR}$ code is unique and unaltered so the teachers can place this QR code into a course syllabus or display on a screen for students to scan and join that classroom. A class teacher can invite other teachers to share the student learning data by sending the relevant QR code as an image file to the other teachers who then scan the QR code to join the classroom.

(iv) Name Student \& Co-teacher: A class teacher must verify requests for access of students and co-teacher(s) to join the classroom. An example form that lists all such requests is shown in Figure 4, with different features for students and co-teacher(s).

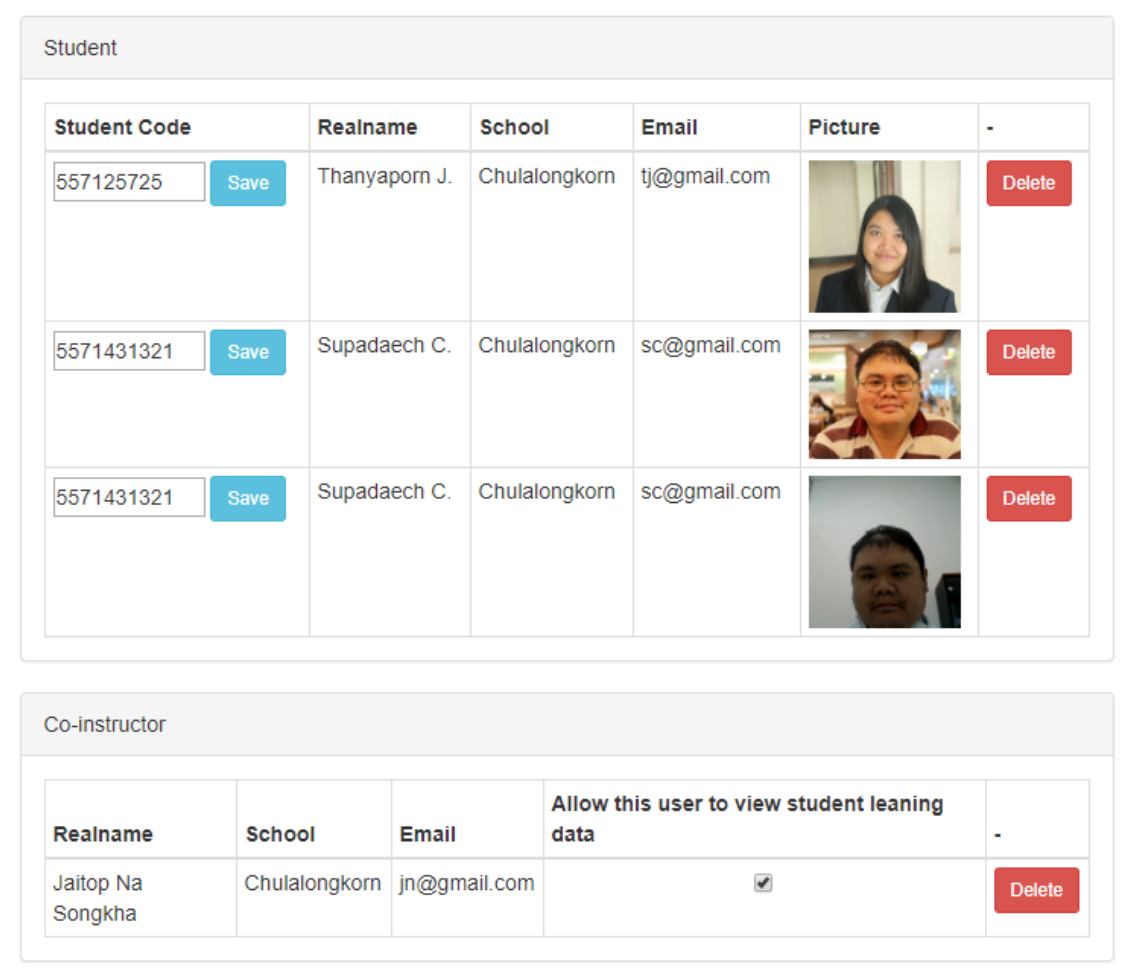

Fig. 4. Student and co-teacher confirmation form

In the case of a student requesting to join the virtual class, the teacher must assign a student code to each student. The student code could be the student's ID number or the order of students in the class. In the case that a student uses more than one mobile device accessing the AR book application, it results in that student then appearing twice in the list (two rows). The teacher must then assign a student code representing the same student to have the same value since WeLearn LMS aggregates the learning data of a student who has the same student code into the same set and assumes that they are the same student when preparing the students' academic summary report. 
In the case of a co-teacher requesting to join a class, the teacher who created the class must first grant permission to allow the user to view the student learning data and to be able to access the student's information. However, co-teacher(s) are not allowed to modify classroom information or manage student lists or other co-teachers.

Report: Information from the AR book (section 2.1.2) can be employed to generate a report that reflects the student's behavior as follows.

(i) Report of the time spent in the examination: If the student spends very little time completing the test and correctly answers all the questions, it could be anticipated that the student can learn quickly and understands the content in that matter very well, or may simply be repeating the answers from a friend who has completed this test before.

(ii) Report the number of times a student answered a question wrongly: This shows how a student understands each content. In the event a student makes many mistakes and takes a long time to complete the examination, it is anticipated that the student is not very well aware of the matter. The teacher should then help to explain or review the contents corresponding to that examination.

(iii) Report the time interval between when a student starts and completes the examination and the examination due date: This reflects the student's behavior on lesson planning as the student may complete all examinations on the last day before submitting the work, or divide it into day-to-day examinations or complete the examination in advance before the due date.

Teachers obtain additional information from the report as mentioned above that automatically collects data from a trackable AR book introduced in this research. All reports are automatically generated and presented in the LMS system. The teachers can employ such information to examine the learning behavior of the whole class and individual students to promote their teaching quality.

\section{Evaluation Method}

The objective of this evaluation was to inquire about the impression of the teachers on the proposed LMS system and whether or not to employ the system in the educational practice. Thus, the evaluation tools applied in this research were an in-depth interview and usability test.

The teachers were selected by purposive sampling where each teacher must meet the following four criteria:

- Be a school teacher in a science education group, as the group has a large number of additional media besides textbooks and they must be familiar with electrical circuits.

- For high school teachers, the age of their students must be sufficient that they are capable of using a computer and mobile device.

- Teachers must not be more than 40-y-old, to diminish the difficulty of being unfamiliar with computers and mobile devices.

- Teachers in schools located in the Bangkok Metropolitan Region with broadband high-speed internet services and $3 \mathrm{G}$ mobile phone network service availability. 
The nine teachers selected (meeting the above criteria) in this research can be classified according to the size and location of their school as shown in Table 1.

Table 1. Summary details of the nine selected teachers

\begin{tabular}{|l|c|c|c|}
\hline \multicolumn{1}{|c|}{ School location } & $\begin{array}{c}\text { Number of students in the } \\
\text { school }\end{array}$ & Number of schools & Number of subjects \\
\hline Bangkok (Capital) & $1000-1500$ & 2 & 3 \\
\hline Bangkok (Capital) & $1500-2000$ & 1 & 1 \\
\hline Bangkok (Capital) & $>2000$ & 1 & 2 \\
\hline Samutprakarn (Metropolitan) & $<500$ & 2 & 3 \\
\hline
\end{tabular}

All nine teachers participated individually and not on the same day. Trial locations took place in the schools where the participating teacher taught during the time they normally taught their subject. The trial took approximately $30 \mathrm{~min}$, and the teacher received 500 baht (approximately 15 USD) in compensation.

During each trial there were two researchers present to perform the trial. One researcher proposed the questions and handled the activities, while the other researcher was responsible for taking notes and observing the teacher's behavior.

The activities in the trial were as follows.

(i) Brief introduction: A self-introduction section between the researchers and teachers to inform them about all the activities in the trial.

(ii) System demonstration: The teachers were required to watch the system introduction video, both for the AR Book section, which was presented from the students' perspective and includes the registration and use of the application, and the WeLearn LMS section, which was displayed in the teacher view in the registration, classroom creates, steps to manage the classroom and performance of the student learning behavior.

(iii) System trial: In this activity, the teacher participated in the trial with three subactivities of (a) registration of students according to the process presented in section 2.1.3, (b) completing the test according to section 2.1.2, and (c) register, to create a classroom and manage, 20 simulated students according to the process presented in Section 2.2.2. The system had a list of 20 simulated students with four duplicated student names, totaling 24 students. Teachers are required to specify the ID of the students from the provided list of names. There was no time limit or timer during the completion of these three sub-activities. The researcher explained the activities the teacher was required to complete. The teacher then completed the activities ( $3 \mathrm{a}$ to $3 \mathrm{c}$ above). The researcher did not provide any advice to the teacher while they were completing these activities. In the event the teacher asked questions, the researcher only answered any question related to the topic asked by the teacher.

(iv) Interview about the proposed system: In this activity, the researcher asked for impressions from the teacher about activities $3 a-3 c$. The four questions used in the inquiry were as follows:

(a) What criticisms do you have on getting students to complete their tests via the AR Book?

(b) What are your opinions on the classroom creates function and adding 20 students to the classroom? 
(c) What commentaries do you have on the LMS system results graph?

(d) If you have to employ the AR Book in teaching and learning, what activity will you employ the AR Book in and how?

The answers to these questions revealed the teachers' attitudes towards if the proposed system would be suitable in teaching or not, and which parts need to be improved or considered further.

\section{$4 \quad$ Results and Discussion}

The results of the trial were taken from an interview of the proposed system activity, and for every question in the activities are as follows:

\subsection{What criticisms do you have on getting students to complete their tests via the AR Book?}

All teachers (9/9) saw the AR Book as an interesting teaching material and believed that the students will relish and be interested in this tool, providing them with an opportunity to complete assignments on their own and without any harm while doing experiments. However, some teachers (4/9) felt that the approach taken in the development of the AR examination could be improved, in that the video that introduces the system and suggestions in the system may not be sufficient for students to understand how to complete the examination for the first time.

\subsection{What are your opinions on the classroom creates function and adding 20 students to the classroom?}

All the teachers agreed that adding a classroom and managing 20 students into the class presented no problem. However, some teachers (3/9) commented that there might be difficulty in the case that a student changes their device, where the teacher must proceed to assign the student code before the student starts their study. In some cases, the teacher may not have the time or may forget to do so, which will result in the student being unable to access the system and so may cause a bad experiences for the student.

Also, it was suggested (2/9) that this process can be improved by allowing the teacher to assign a list of students and create a password for each student instead and then use the password for the registration process so that teachers do not waste time in doing the aforementioned activities.

\subsection{What comments do you have on the LMS system results graph?}

Every teacher said that the LMS system results graph were useful in analyzing the students' behavior and they proposed methods to improve the application of the results graph. For example, when the graph shows that students usually completed their homework three days before the deadline, the teacher doesn't need to assign them homework 
for a long time beforehand. If the student had a large number of wrong submissions to complete the tests correctly, the teacher may explain the content in the subject more as the students may not understand the material very well.

Many teachers (7/9) had a question on the conversion from the results graph to the student's score. The researcher had to clarify that the graph is intended to present each student's performance and behavior data only. The teacher will have to set the criteria for the scoring on his/her own. For example, if the students complete this examination before the scheduled date, they will get the full score but gradually receive an increasing penalty (score deduction) with increasing time after the deadline. The data can be used to define the students' cooperation in the course and can be employed as a score for participation in the activity. However, the teachers requested to include that function to the LMS to work with a single system.

\subsection{If you have to employ the AR Book in teaching and learning, what activity will you apply the AR Book in and how?}

The teachers offered two methods to apply the media:

(i) Utilizing as an extra material used in conjunction with the leading textbook along with the flipped classroom teaching method. The teacher assigns the students to study on their own before the lesson, and each student brings their results to the classroom, which then directs the activities to summarize the lesson learned in the classroom. This method corresponds to the design of this research.

(ii) Applying the AR Book in the classroom activities to allow students to study lessons and complete their tests in the AR Book, where the teacher is able to review in a real-time system the student's progress in learning and which parts of the content that students made many mistakes on. However, application in the classroom was not anticipated in the initial design goal.

This question caused the teachers (6/9) to come up with questions about the use-case of the systems. Questions to be considered included:

- Is it possible to use the system if the internet cannot be connected? This question was brought up in the case of students who did not pay for a mobile internet package and cannot connect to the school Wi-Fi.

- Is this system compatible on a computer? This question was brought up in the case of the disparity of the device, for example, the efficiency of the processing and the screen size, which could be solved by employing the system on a school computer room (as long as every teacher's school had a computer lab room).

- Is it possible to employ the system if the mobile device is rented? This question was brought up in the case where the school provided a tablet device as a public device for students to borrow to complete various activities.

- Is it possible to work in a group? This question was brought up in the case of employing the system with a group activity in the classroom.

The researcher discovered more about the teacher and about mobile devices and Internet usage, where in community schools about 3-5 students per class do not own a mobile device and many of the other students do not apply for mobile internet packages. 
This group of students will use the internet from the school's Wi-Fi or Broadband Internet at the student's home, which will lead to many difficulties when employing this AR Book as an extra learning material as the students have to pay for the purchase of mobile devices or internet packages to complete their homework.

The teachers were able to manage their classroom and did not encounter any difficulties that lead to the proposed LMS becoming an unwanted system. However, the teachers encountered problems and came up with suggestions in the student management activities function about when students change their device. It was suggested that this activity should be completed automatically on the system.

For the AR Book, it was found that the teachers found the AR Book interesting and useful for the students. Also, the teachers could apply the AR Book, according to the use case, to fulfill the course objectives. However, for completing the examination, the AR Book should be designed to support more use cases and be able to run on other platforms besides mobile devices.

\section{$5 \quad$ Conclusion and Future Work}

This research presents a trackable augmented learning media system that contains an AR book for students and a cloud-based WeLearn LMS for teachers. Students study materials and take examinations provided by the AR book. Students' learning activities are collected by the AR book application and sent to the WeLearn LMS. Teachers register, create a classroom and manage students in the WeLearn LMS manually. The WeLearn LMS summarizes the students' learning log and presents student performance reports.

The opinion from the test teachers revealed that this proposed trackable augmented learning media system is suitable for classroom application and especially that the student performance reports can generate new pedagogy and improve teaching methods by using real-time data from reports to adjust the difficulty of a content corresponding to the students' behaviors.

The "Name Student \& Co-teacher" process (section 2.2.2) needs to be improved in the case of a student changing a mobile device because this activity randomly occurs and is a crucial task for students. If teachers forget to perform this activity, the students' learning logs aren't collected. This task may be solved by using artificial intelligence to automatically recognize a new student's picture and link a new student's request with his/her previous account.

The use cases of the proposed system need to be considered more. The teachers asked about unusable use cases, such as with a computer, or a rented device or without internet. The teacher's requests were derived from the limitation of student and school resources (finances), such as for mobile phones and internet/Wi-Fi packages. In future work, the availability of ICT for both students and schools must be considered in designing use cases of the system such that most if not all of the students can gain access. 


\section{Acknowledgement}

This research was supported by Ratchadapisek Somphot Fund for Postdoctoral Fellowship, Chulalongkorn University.

\section{$7 \quad$ References}

[1] H. Coates, R. James, and G. Baldwin, "A critical examination of the effects of learning management systems on university teaching and learning," Tertiary Education and Management, vol. 11, pp. 19-36, 2005. https://doi.org/10.10 80/13583883.2005.9967137

[2] N. Cavus, H. Uzunboylu, and D. Ibrahim, "Assessing the success rate of students using a learning management system together with a collaborative tool in web-based teaching of programming languages," Journal of Educational Computing Research, vol. 36, no. 3, pp. 301-321, 2007. https://doi.org/10.2190/t728-g676-4n18-6871

[3] S. Lonn, and S. D. Teasley, "Saving time or innovating practice: Investigating perceptions and uses of Learning Management Systems," Computers \& Education, vol. 53, no. 3, pp. 686-694, 2009. https://doi.org/10.1016/j.compedu.2009.04.008

[4] U. Köse, "A blended learning model supported with Web 2.0 technologies," Procedia-Social and Behavioral Sciences, vol. 2, no. 2, pp. 2794-2802, 2010. https://doi.org/10.1016/j.sbspro.2010.03.417

[5] D. Holt, and D. Challis, "From policy to practice: One university's experience of implementing strategic change through wholly online teaching and learning," Australasian Journal of Educational Technology, vol. 23, no. 1, 2007. https://doi.org/10.14742/ajet.1276

[6] I. M. Romi, "A Model for e-Learning Systems Success: Systems, Determinants, and Performance," International Journal of Emerging Technologies in Learning (iJET), vol. 12, no. 10, pp. 17, 2017-11-02, 2017. https://doi.org/10.3991/ijet.v12i10.6680

[7] G. Kakasevski, M. Mihajlov, S. Arsenovski, and S. Chungurski, "Evaluating usability in learning management system moodle." Proc. of ITA $200830^{\text {th }}$ International Conference on Information Technology Interfaces, Croatia. https://doi.org/10.1109/iti.2008.4588480

[8] R. E. West, G. Waddoups, and C. R. Graham, "Understanding the experiences of instructors as they adopt a course management system," Educational Technology Research \& Development, vol. 55, no. 1, pp. 1-26, 2007. https://doi.org/10.1007/ s11423-006-9018-1

[9] P. A. Ertmer, "Teacher pedagogical beliefs: The final frontier in our quest for technology integration?," Educational Technology Research \& Development, vol. 53, no. 4, pp. 25-39, 2005. https://doi.org/10.1007/bf02504683

[10] Clemons, Eric K., Sashidhar P. Reddi, and Michael C. Row, "The impact of information and communication technology (ICT) on the management practices of Malaysian Smart Schools," Journal of Management Information Ssystems, vol. 24, no. 2, pp. 201-211, 2004.

[11] R. Benson, and T. Palaskas, "Introducing a new learning management system: An institutional case study," Australasian Journal of Educational Technology, vol. 22, no. 4, 2006. https://doi.org/10.14742/ajet.1285 
[12] Q. N. Naveed, and N. Ahmad, "Critical Success Factors (CSFs) for Cloud-based ELearning," International Journal of Emerging Technologies in Learning (iJET), vol. 14, no. 01, pp. 10, 2019-01-17, 2019. https://doi.org/10.3991/ijet.v14i01.9170

[13] N. Temiyasathit, P. Punyabukkana, and A. Suchato, "Course periodic behavior modelling and its application in LMS activity prediction." Global Engineering Education Conference (EDUCON), 2016 IEEE, pp. 1164-1174. IEEE, 2016. https://doi.org/10.1109/educon.2016.7474703

[14] A. Javornik, "Augmented reality: Research agenda for studying the impact of its media characteristics on consumer behaviour," Journal of Retailing Consumer Services vol. 30, pp. 252-261, 2016. https://doi.org/10.1016/j.jretconser.2016. 02.004

[15] R. Grasset, A. Dunser, and M. Billinghurst, "The design of a mixed-reality book: Is it still a real book?." Proceedings of the 7th IEEE/ACM International Symposium on Mixed and Augmented Reality, pp. 99-102. IEEE Computer Society, 2008. https://doi.org/10.1109/ismar.2008.4637333

[16] A. Clark, and A. Dünser, "An interactive augmented reality coloring book." 2012 IEEE Symposium on $3 D$ User Interfaces (3DUI). IEEE, pp. 7-10. https://doi.org/10.1109/3dui.2012.6184168

[17] K. M. Ala-Mutka, "A survey of automated assessment approaches for programming assignments," Computer Science Education, vol. 15, no. 2, pp. 83-102, 2005. https://doi.org/10.1080/08993400500150747

[18] Q. Wang, H. L. Woo, C. L. Quek, Y. Yang, and M. Liu, "Using the Facebook group as a learning management system: An exploratory study," British Journal of Educational Technology, vol. 43, no. 3, pp. 428-438, 2012. https://doi.org/10.1111/j.1467-8535.2011.01195.x

[19] R. Dellos, "Kahoot! A digital game resource for learning," International Journal of Instructional Technology Distance Learning, vol. 12, no. 4, pp. 49-52, 2015.

[20] H. Bicen, and S. Kocakoyun, "Perceptions of Students for Gamification Approach: Kahoot as a Case Study," International Journal of Emerging Technologies in Learning (iJET), vol. 13, no. 02, pp. 22, 2018-02-27, 2018. https://doi.org/10.3991/ ijet.v13i02.7467

\section{Authors}

Supadaech Chanjaradwichai is a member of the Department of Educational Technology and Communications, Faculty of Education, Chulalongkorn University, 254 Phayathai Road, Pathumwan, Bangkok 10330, Thailand. He works as a researcher and an undergraduate lecturer. His interests are in learning management systems, augmented reality, internet of thing and artificial intelligence.

Jaitip Na Songkhla is an Associate Professor and a Director of Innovative Educational Technology (iNET), Chulalongkorn University, 254 Phayathai Road, Pathumwan, Bangkok 10330, Thailand. Her works have supported a wide range of students from K-12, Teachers' education and learners in the workplace, and Lifelong Learning, covering a new age of learning media. Among her researches and practices, several of her learning support products based on AR Technology have brought an impact solu- 
tion in the light of learners' Higher Order of Thinking in Situated Learning and Cognitive Apprenticeship with an authentically effective learning engagement and workplace performance support.

Thanyaporn Chiasiriphan is a staff member at the Faculty Promotion Committee Secretary, Chulalongkorn University, 254 Phayathai Road, Pathumwan, Bangkok 10330, Thailand.

Article submitted 2019-01-19. Resubmitted 2019-04-08. Final acceptance 2019-04-09. Final version published as submitted by the authors. 